\title{
Integration adsorption chillers with conventional power plant
}

\author{
Karol Sztekler ${ }^{1, *}$, Wojciech Kalawa ${ }^{1}$, Sebastian Stefański ${ }^{1}$, Łukasz Mika ${ }^{1}$, Jarosław \\ Krzywański ${ }^{2}$, Karolina Grabowska ${ }^{2}$ and Wojciech Nowak $^{1}$ \\ ${ }^{1}$ AGH University of Science and Technology, Faculty of Energy and Fuels, 30-059 Cracow, Poland \\ ${ }^{2}$ Jan Dlugosz University of Czestochowa; Faculty of Mathematics and Natural Sciences, 42-200 \\ Czestochowa, Poland
}

\begin{abstract}
According to predictions, electricity consumption in developed countries will increase three times by 2020 compared with 1970 . In contrast, in developing countries, where the population may double by 2020 relative to 1970 , there may even be a twentyfold increase in electricity consumption [1]. Other sources predict that increases in electricity demand by 2030 will be approx. $2 \div 3 \%$ a year. With such a high rate of development of the world economy, the electricity demand will be increasing. Thus, using only renewable sources to satisfy the demand for energy is insufficient and will remain so in the near future. Coal will remain the predominant fuel used to produce electricity. One of the ways to reduce the adverse effect of fossil fuels on the natural environment is to increase the efficiency of use of primary energy. Electricity production is associated with large losses, including in the form of heat which can be used to produce cold with adsorption chillers that can be powered by low-temperature heat. The paper presents the possibility to employ adsorption chillers in power units in order to increase the efficiency of electricity production. Simulation calculations were performed using Sim tech's IPSEPro software.
\end{abstract}

\section{Introduction}

The electricity demand in Poland is increasing and this tendency will be maintained according to forecasts. According to the predictions presented at a conference from the series of conferences called Energy Raw Material and Energy Issues in the National Economy, which took place in Zakopane in 2009, an increased demand for primary energy is forecast. The average annual increase from 2015 to 2030 will be approx. 7 Mtoe. Toe means a tonne of oil equivalent which is equal to energy on the order of $11.63 \mathrm{MWh}$ [2]. This growth will force an increase in the installed generation capacity in the national power system. This in turn involves large investment outlays. Electricity production in Poland is mostly based on conventional fuels, mainly hard coal and brown coal (79\% in total), and the following ones have a smaller share in electricity production: RES 13\%, gaseous fuels 5\%, biomass and other carriers 3\%. 166.6 TWh of electricity were produced in Poland in 2016 and its consumption amounted to $159.1 \mathrm{TWh}$. In 2016, the total installed thermal capacity at licensed heat

\footnotetext{
* Corresponding author: sztekler@agh.edu.pl
} 
producers was 54,259.8 MW, and the heat generation capacity - 53,434.7 MW, of which the heat supplied to customers connected to the network amounted to $235,545.9$ TJ. In the case of heat production, the predominant fuel used for this purpose is coal $(75 \%)$ followed by gaseous fuels (7,2\%) and RES (7,6\%). 2,230,263,334 GJ of energy from coal fuels were used up when producing heat in cogeneration [3]. The use of fossil fuels has many negative effects on the environment such as global warming, acid rains, smog, soil and water pollution. In addition, the global reserves of energy raw materials are being reduced. Counteracting these phenomena consists in increasing the efficiency of electricity production and searching for more efficient methods of conversion of chemical energy from fuel into electricity and heat or substituting the fuel for one that is more environmentally friendly. In line with the Polish energy policy, coal will remain the predominant fuel used to produce electricity and heat until 2050. Therefore, any actions aimed at limiting the adverse effect of coal combustion products on the natural environment are fully justified. A serious problem for the Polish power industry is low efficiency of operation of power plants (33-34\%). Low efficiency increases the consumption of chemical fuels, which leads to higher emissions into the environment and increased costs of energy production. The current state of affairs is improving slowly and modern power units in power plants are being gradually commissioned. However, many years of negligence require expensive, long-term investments. Energy generation efficiency improvements take many forms, one of them being the use of cogeneration and trigeneration that reduce the amount of heat released into the environment and make it possible to generate electricity, heat and cold at the same time. On the graph below, one can see the effect of increased efficiency of electricity production on $\mathrm{CO}_{2}$ emissions [4-6].

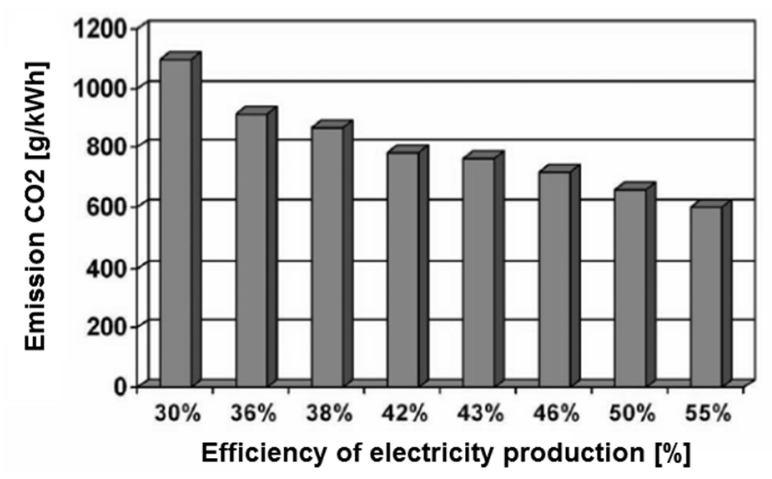

Fig. 1. Effect of increased efficiency of electricity production on $\mathrm{CO}_{2}$ emissions [7].

Therefore, one of the ways to limit the negative effect of professional power industry on the natural environment is to increase the efficiency of electricity production by using an adsorption chiller to produce ice water used for the purposes of air-conditioning or also other engineering processes, which can use the chemical energy of fuel more efficiently $[7,8]$.

\section{Modelling process}

\subsection{Adsorption chillers}

Adsorption refrigeration equipment gains more and more popularity in the field of refrigeration engineering. Adsorption is a process of binding adsorbate particles (the part being captured) with an adsorbent (the capturing part). Adsorbate particles are located near the borderline between adsorbent-adsorbate phases. At this point, one can conclude on the basis of this description that it is a process that is almost identical to absorption, but there is 
a fundamental difference between them - the adsorption process takes place on the adsorbent's surface, whereas absorption is a process of permeation inwards. The phenomenon of adsorption is accompanied by surface energy - it is the energy resulting from energy differences between particles on the surface relative to particles in the adsorbent. The basic parts that this device consists of are a condenser, an evaporator and an adsorbent bed (Fig. 2).

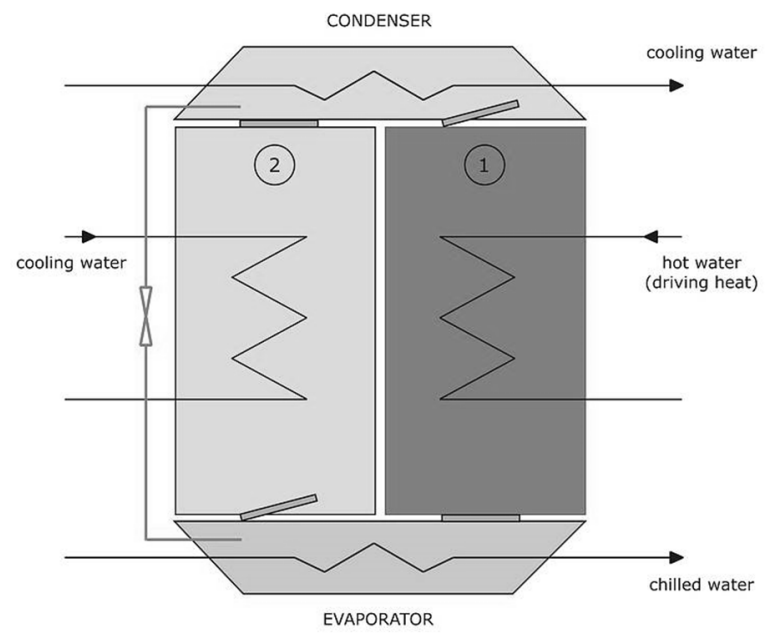

Fig. 2. Adsorption cooling-desalination system [9].

The principle of operation of an adsorption cooling-desalination system (Fig. 2.) consists in evaporating the refrigerant in the evaporator at reduced pressure. The process takes place without using a mechanical compressor whereby the thermal effect of adsorption and desorption is employed. The system's operation is cyclical whereby the adsorption and desorption (bed regeneration) processes take place alternately. Refrigerant vapour carried away from the evaporator is adsorbed in the adsorption bed, which is accompanied by the release of heat that is absorbed by the cooling water. In order to allow further functioning of the bed, it is necessary to remove the refrigerant (adsorbate) from the adsorbent (desorption). This process requires supply of heat from an external source. Refrigerant vapour released in the desorption process are transported to the condenser. In a closed system, the condensate from the condenser goes back to the evaporator. It is possible to use an adsorption refrigeration unit with an open system where water is the refrigerant. Continuous water supply from an external source results in production of a condensate that is free of substances dissolved in the supply water. In the case of supplying the system with saline water, an additional product (aside from the refrigeration effect) is desalinated water. First hybrid systems using the adsorption cooling-desalination system provided a heating and refrigerating effect. Adsorption refrigeration equipment does not need electricity to operate - it is powered by supplying it with heat [10-14]

In addition to differences from the chemical viewpoint, adsorption equipment stands out with respect to a few aspects when compared to absorption equipment. First of all, adsorption equipment can work where the temperature of a waste heat source is not sufficient to use absorption equipment. While absorption systems work at a temperature of refrigerant needed for desorption of $90^{\circ} \mathrm{C}$, adsorption equipment works at a temperature of waste heat of $50^{\circ} \mathrm{C}$ (Fig. 3). A low desorption temperature allows more universal application and use of lowtemperature heat. Operation of an adsorption chiller with silica gel - water working pair is possible from approx. $43^{\circ} \mathrm{C}$ in the case of two-stage equipment and $62^{\circ} \mathrm{C}$ - in the case of single-stage equipment $[8,9,14,15]$. 


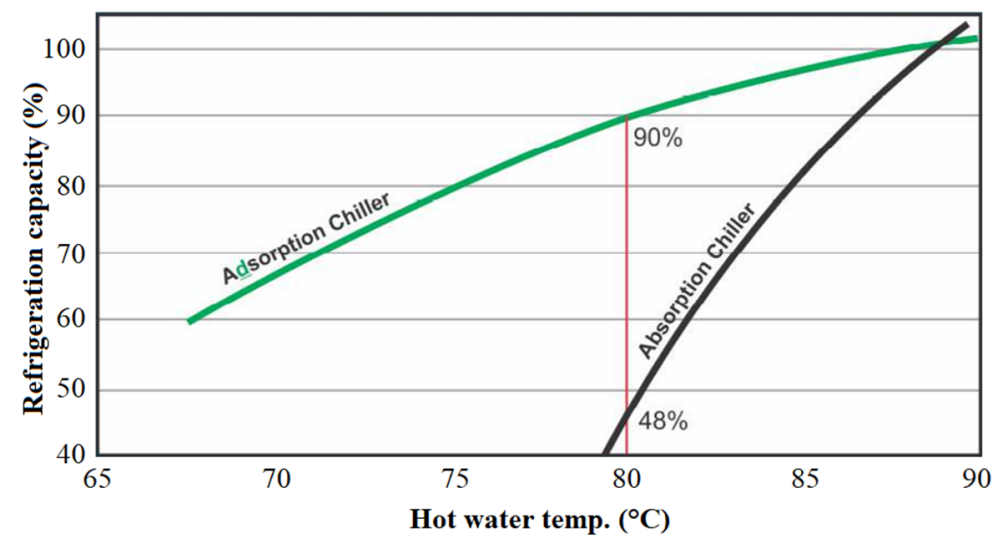

Fig.3. Effect of hot water temperature on the refrigeration (cooling) capacity of adsorption-absorption chillers [16].

Thanks to this, adsorption equipment can be used where absorption equipment does not work efficiently because the temperature of water is too low. In addition, adsorption equipment is less prone to corrode at high temperatures and is not affected by the issue of crystallisation that occurs in lithium bromide equipment. An additional advantage is the ability to work in conditions where strong vibrations occur. This is due to the fact that adsorbents have a solid structure, whereas the solution in absorption equipment is a liquid, so strong vibrations can cause interference in its flow. The biggest disadvantage of this type of equipment is low COP (coefficient of performance) - it does not exceed 0.6, whereas the $\mathrm{COP}$ in absorption equipment is at least 0.7. Equipment of this type can be successfully employed anywhere the temperature of supply water is lower than $90^{\circ} \mathrm{C}$. Figure 4 shows the effect of the temperature of supply water used in adsorption systems on the COP.

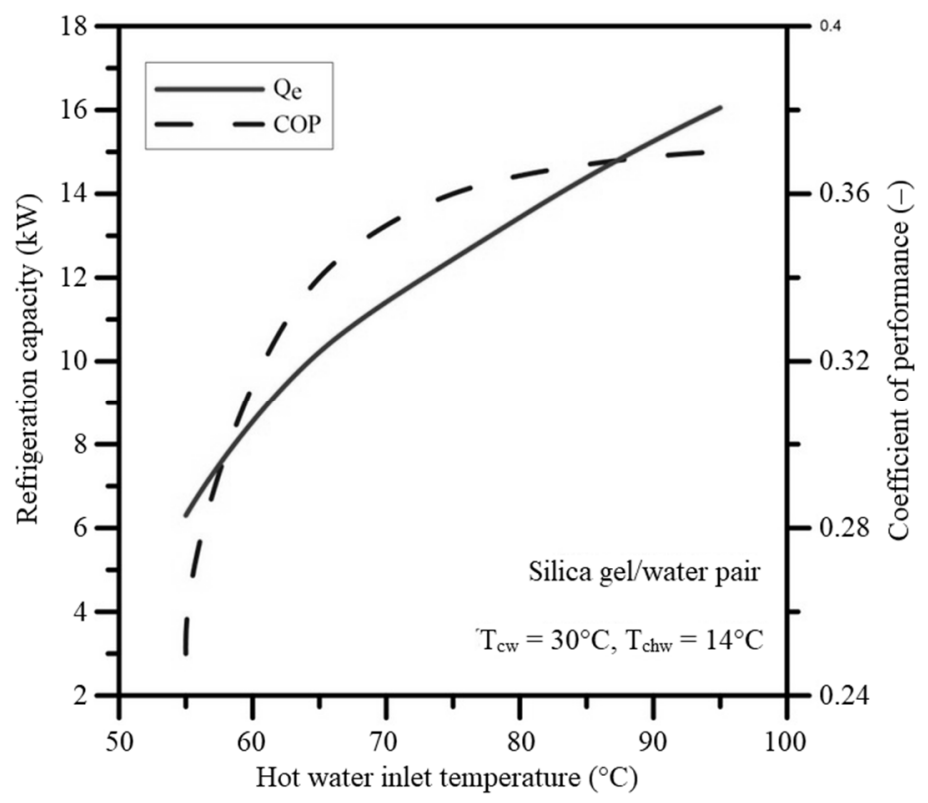

Fig. 4. COP values of a silica gel - water chiller depending on the temperature of supply water [15]. 
The optimal solution in a given case will be to employ an adsorption chiller using a silica gel - water system. A good example of such equipment can be a refrigeration unit made by Bry-Air, model: ADC Series F-FRAME F-330. It is capable of working at supply temperatures in the range from $52^{\circ} \mathrm{C}$ to $93^{\circ} \mathrm{C}$, producing ice water with a temperature of $7.2^{\circ} \mathrm{C}$. A drop in the temperature of water supplying the chiller (difference between inlet water temperature and water exiting the chiller) specified in the technical specification of the model is $\Delta \mathrm{T}_{\mathrm{z}}=6.6^{\circ} \mathrm{C}$. Power consumption is small: $1.3-2.4 \mathrm{~kW}[16]$.

Table 1. Technical specification of Bry-Air chiller, model: ADC Series F-FRAME F-330 [12].

\begin{tabular}{|l|c|}
\hline Cooling capacity & $1.180 \mathrm{~kW}$ \\
\hline Power consumption & $1.3-2.4 \mathrm{~kW}$ \\
\hline Refrigerant type & water \\
\hline Chilled water - Inlet Temperature & $12.8^{\circ} \mathrm{C}$ \\
\hline Chilled water - Outlet Temperature & $7.2^{\circ} \mathrm{C}$ \\
\hline Condenser Water - Inlet Temperature & $29^{\circ} \mathrm{C}$ \\
\hline Condenser Water- Outlet Temperature & $35^{\circ} \mathrm{C}$ \\
\hline Hot Water Inlet Temperature & $52^{\circ} \mathrm{C}$ \\
\hline Hot Water Outlet Temperature & $45.4^{\circ} \mathrm{C}$ \\
\hline Hot Water for regeneration Temperature range & $52^{\circ} \mathrm{C}-93^{\circ} \mathrm{C}$ \\
\hline Temperature drop for regeneration process & $\Delta \mathrm{t}=6.6^{\circ} \mathrm{C}$ \\
\hline
\end{tabular}

The value of the coefficient of performance of a chiller using the silica gel - water system is variable and strongly dependent on the temperature of supply water. On the basis of the graph from Fig. 4, the value of the COP for hot water temperature of $52^{\circ} \mathrm{C}$ is $\mathrm{COP}_{27^{\circ} \mathrm{C}}=0.28$.

Adsorption cooling systems are being dynamically improved. Their range of application is expanding, and in combination with renewable energy sources they can make a cheap source of cooling. Commercialisation of the solutions found in adsorption cooling industry is possible if the most fundamental disadvantages are eliminated, i.e. the small cooling capacity in relation to the mass of the plant and the fluctuations in the cooling performance resulting from the cyclic nature of operation.

\subsection{Conventional power plant}

Research and modelling of a process increasing the efficiency of the thermal cycle in this paper are based on measurements of an actual thermal system, for operation close to nominal values. The system implements the Rankine cycle, called the " $200 \mathrm{MW}$ power unit". It is a typical power unit working in Polish power plants. Currently, there are 44 operational plants of this type in Poland whose total installed capacity is $11 \mathrm{GW}$, which constitutes $30 \%$ of the total installed capacity [17]. The main parameters of the power plant were presented in Table 2. 
Table 2. Main parameters of the power plant [17].

\begin{tabular}{|c|c|c|c|c|}
\hline Parameter & \multicolumn{2}{|c|}{ Value } & \multicolumn{2}{|c|}{ Unit } \\
\hline Live steam flow $\dot{m}_{k}$ & \multicolumn{2}{|c|}{179.0} & \multicolumn{2}{|c|}{$\mathrm{kg} / \mathrm{s}$} \\
\hline Reheated steam flow $\dot{\mathrm{m}}_{\mathrm{w}}$ & \multicolumn{2}{|c|}{150.3} & \multicolumn{2}{|c|}{$\mathrm{kg} / \mathrm{s}$} \\
\hline Live steam, pressure $p_{p} /$ temperature $T_{p}$ & 128.0 & 535.0 & bar & ${ }^{\circ} \mathrm{C}$ \\
\hline Reheated steam, pressure pw /temperature Tw & 25.67 & 535.0 & bar & ${ }^{\circ} \mathrm{C}$ \\
\hline Generator power $\mathrm{P}_{\mathrm{g}}$ & \multicolumn{2}{|c|}{215.84} & \multicolumn{2}{|c|}{ MW } \\
\hline Net efficiency of the power unit $\eta_{\text {bnt }}$ & \multicolumn{2}{|c|}{38.71} & \multicolumn{2}{|c|}{$\%$} \\
\hline $\begin{array}{l}\text { EUF } \\
\text { (indicator of use of the chemical energy of fuel for } \\
\text { the production of electricity in the power plant) }\end{array}$ & \multicolumn{2}{|c|}{40.95} & \multicolumn{2}{|c|}{$\%$} \\
\hline
\end{tabular}

Hot water with a temperature of $52^{\circ} \mathrm{C}$, produced in the heat exchanger (1) supplied with flue gases with a temperature of $130^{\circ} \mathrm{C}$, which are cooled down to a temperature of $85^{\circ} \mathrm{C}$ in line with the literature data [18], is used to supply the adsorption chiller. Water used for the process of condensation of the circulating refrigerant in the adsorption chiller comes from the main condensate cycle of the power plant's cycle (2). Once it has absorbed the heat in the condenser, it is returned between low-pressure exchangers (3). A diagram of the thermal cycle of a conventional power plant along with the installed adsorption chiller was shown in Figure 4.

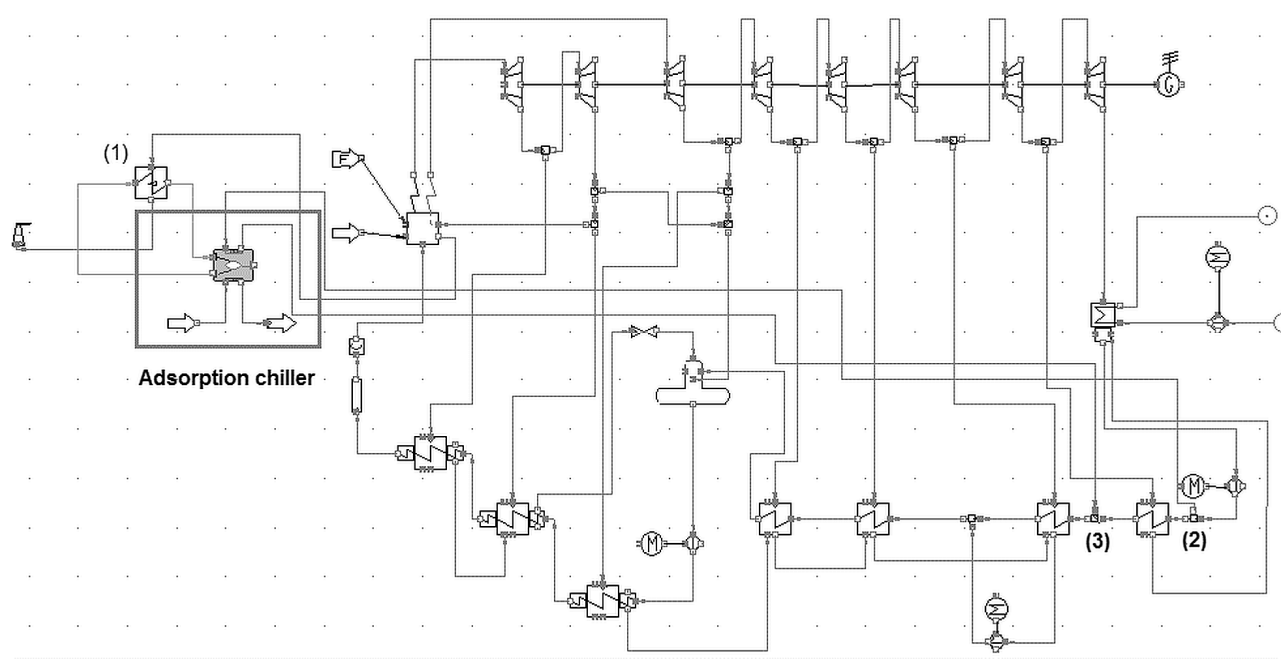

Fig.5. Power plant integrated with adsorption chiller.

The use of this type of solution causes reduction of losses associated with the production of electricity and utilisation of waste heat in the power plant. Flue gas with such a high temperature can be further usefully used to produce hot water that can be later employed to supply adsorption chillers, the created ice water being used for useful purposes as well. The total cooling capacity of an adsorption chiller is $3.45 \mathrm{MW}$, whereas the flows of circulating refrigerant (needed for the chiller to work) drawn from the main cycle of the power plant do not affect negatively the operation of the power unit. 
Table 3. Summary of the most important data

\begin{tabular}{|l|c|c|c|}
\hline \multicolumn{1}{|c|}{ Parameter } & Symbol & Value & Unit \\
\hline Electrical capacity & $\mathrm{N}_{\mathrm{el}}$ & 215.84 & $\mathrm{MW}$ \\
\hline Maximum heat delivered to the adsorption chiller & $\dot{\mathrm{Q}}_{\mathrm{z}}$ & 12.34 & $\mathrm{MW}$ \\
\hline Maximum cooling capacity & $\dot{\mathrm{Q}}_{\mathrm{ch}}$ & 3.45 & $\mathrm{MW}$ \\
\hline COP (coefficient of performance) of Bry-Air chiller ADC & $\mathrm{COP}$ & 0.28 & - \\
\hline $\begin{array}{l}\text { EUF } \\
\text { (indicator of use of the chemical energy of fuel in the } \\
\text { system for the production of electricity and chilled water) }\end{array}$ & EUFT $_{\mathrm{T}}$ & 43.3 & $\%$ \\
\hline
\end{tabular}

\section{Summary}

The main purpose of this paper was to analyse the effect of adsorption chillers on the improvement of energy efficiency of a conventional power plant. Activities aimed at its improvement and efficient use of non-renewable energy sources are becoming an increasingly important aspect of work of plants generating electricity. This brings measurable benefits both for the natural environment and the enterprise itself (profits from fuel saving or the White Certificates). As a result of use of adsorption cooling-desalination systems, a $2.35 \%$ increase in the use of chemical energy of fuel occurs compared to the base system where only electricity is produced. Trigeneration and cogeneration systems have a significant impact on the reduction of losses associated with production of electricity. In the analysed case, the use of adsorption chillers has a positive effect on the power unit's operation and results in more efficient use of the chemical energy of fuel. The generated cold in the amount of $3.45 \mathrm{MW}$ can be later used for process purposes, thus generating an additional profit associated with the sale of a product which is cold. Adsorption cooling-desalination systems are used more and more and, in combination with renewable energy sources, they can be a cheap source of cold. Commercialisation of adsorption refrigeration solutions will be possible, provided that the biggest flaws are eliminated, i.e. small cooling capacity relative to the weight of the plant and cooling capacity fluctuations resulting from cyclical nature of operation. Combining an adsorption chiller with a system of a conventional power plant makes it possible to use excess heat, which is becoming more and more important due to the changing market demand for heat and cold. Currently, plants are being built for central generation of cold that is then distributed to end users.

Acknowledgment The paper was funded from government money Faculty of Energy and Fuels number 11.11.210.376.

\section{References}

1. T. Czakiert, Z. Bis, W. Muskała, W. Nowak, Chemical and Process Engineering, 26, 831 (2005)

2. M. Duda, H. Mikołajuk, S. Okrasa, Prognoza bilansu energetycznego Polski do $2030 \mathrm{r}$. (in Polish), source: https://min-pan.krakow.pl/se/pelne_teksty23/k23z_mk/k23_duda _mikolajuk_okrasa_z.pdf (2009)

3. Statistical Information Centre, Department of Environment and Engergy, Energy, source: https://stat.gov.pl/en/topics/environment-energy/energy/energy-2017,1,5.html (2017) 
4. Directive 2012/27/EU of the European Parliament and of the Council of 25 October 2012 on energy efficiency, amending Directives 2009/125/EC and 2010/30/EU and repealing Directives 2004/8/EC and 2006/32/EC, OJ L 315

5. OECD, Environmental Outlook to 2050 (2012)

6. Z. Kasztelewicz, M. Patyk, Polityka Energetyczna - Energy Policy Journal 18 4, 45 (2015) (in Polish)

7. K. Sztekler, K. Wojciechowski, M. Komorowski, M. Tarnowska, E3S Web of Conferences 14, 01031 (2017)

8. K. Sztekler, M. Komorowski, M. Tarnowska, Ł. Posak, E3S Web of Conferences 10, 00095 (2016)

9. L. Zisheng, W. Ruzhu, Applied Energy 174, 224 (2016)

10. A.A. Askalany, B.B. Saha, K. Kariya, I.M. Ismail, M. Salem, A.H.H. Ali, M.G. Morsy, Renewable and Sustainable Energy Rev. 16, 5787 (2012)

11. S. Mitra, P. Kumar, K. Srinivasan, P. Dutta, Int. J. of Refr. 67, 174 (2016)

12. S. Mitra, K. Thu, B.B. Saha, P. Dutta, Applied Energy 206, 507 (2017)

13. J.X. Zhang, R.Z. Wang, Renewable Energy 27, 401 (2002)

14. G. Najeh, G. Slimane, M. Souad, B. Riad, E.G. Mohammed, Case Studies in Thermal Engineering 8337 (2016)

15. M.G. Gado, E.Elgendy, K. Elsayed, M. Fatouh, Parametric study of an adsorption refrigeration system using different working pairs, Proceedings:17th International Conference on Aerospace Sciences \& Aviation Technology, Cairo, Egypt (2017)

16. Bry-Air technical data, https://www.bryair.com/products-solutions/adsorption-chillers

17. Internal technological documentation from power plants Kozienice, Poland

18. K. Thu, H. Yanagi, B.B. Saha, K.C. Ng, Int J. of Heat and Mass Transfer 65, 662 (2013) 